and, finally, 5) Communication from EMS personnel at the site to their families. The only difficulty with portable cellular telephones was limited battery life which was solved by providing DC (direct current) recharging equipment. In areas where cellular telephone service is available, cellular technology can be a valuable communication tool in disaster management.

\section{IMPLEMENTING AND TESTING THE NATIONAL DISASTER MEDICAL SYSTEM WITHIN A REGION}

William E. Clark, M.S., R Adams Cowley, M.D., Thomas P. Reutershan, M.S. and M.H. Estepp, Baltimore, Maryland, U.S.A.

The United States is implementing the National Disaster Medical System (NDMS) to provide a nationwide network of hospital and medical response capability to care for casualties of a catastrophic medical emergency. A major NDMS exercise was conducted in Prince George's County, Maryland in July 1986 that simulated a fire and explosion at a crowded rock concert. This massive disaster exercise tested emergency response systems in the local jurisdictions and at the federal level. More than 600 moulaged casualties were triaged, treated and transported to more than 50 hospitals in a three-state area during a 6-1/2 hour period. Transportation of patients included the utilization of ambulances, buses, helicopters, a C-130 aircraft, and a specially configured train. A variety of communications systems were used to provide linkages with participating hospitals. Approximately 70 principal representatives of various public and private sector organizations worked together to develop and integrate planning efforts.

\section{CENTRAL VENOUS PRESSURE MONITORING IN HEAT STROKE PATIENTS DURING THE PILGRIMAGE (HAJJ) IN SAUDI ARABIA: A SIMPLE GUIDELINE FOR INDIVIDUAL FLUID REPLACEMENT}

Mohamed A. Seraj, M.D., Ryiadh, Saudi Arabia

To date, standard treatment of heat stroke at the Hajj resuscitation centers has included body surface cooling combined with rapid intravenous infusion of
3 to 4 liters of crystalloids solution at room temperature which resulted in acute overload problems such as heart failure, edema and pneumonia.

Uncontrolled infusion of such generous quantities of crystalloids is hazardous in patients suffering from concomitant disease, and especially in those with a previously compromised cardiovascular system. Safe fluid management in such cases demands careful monitoring of the central venous pressure to ensure against acute fluid overload. The authors therefore conducted a study to monitor CVP and administer fluids in a controlled manner during heat stroke resuscitation. In this study, 32 patients were randomly monitored and it was found that most of the patients were fluid depleted and required only 1-1.5 liters of fluid during an average cooling time of 1 hour. Thus, this study confirmed that unmonitored fluid therapy is hazardous and may increase the preventable morbidity and mortality.

\section{BLUNT MASSIVE PANCREATIC TRAUMA}

Om P. Sharma, M.D., Toledo, Ohio, U.S.A.

Pancreatic trauma entails careful, aggressive management with timely surgical intervention. Pancreatic trauma can be frequently overlooked or underestimated leading to potentially disastrous complications. A few cases of major blunt pancreatic trauma are presented and management reviewed. Prolonged Total Parental Nutrition with adequate nasogastric decompression have changed the outlook for many potential disasters.

\section{AN UNUSUAL EPISODE OF MASSIVE INTOXICATION WITH BARIUM SALTS USED AS ROUTINE CONTRAST MEDIA FOR X-RAY GI SERIES}

\author{
Jose Saldias, M.D., Maria Diaz, M.D. and \\ Freddy Medina, M.D., Lima, Peru
}

We report an unusual episode of massive barium salt intoxication, used as routine contrast media for $\mathrm{X}$-ray GI series.

On August 17th and 18th, 1982, GI X-ray series were performed on a group of patients on an ambulatory basis. They received soluble barium salts, sold to 
the hospital as barium sulfate, and drank a volume consistent to a cup of tea. After a period of approximately 8 hours, the first patient came to the E.D. with severe GI and neurologic symptoms (quadriparesia, arreflexia, diarrhea, vomiting) and a diagnosis of Acute Polirradiculoneuritis was made. None of the medical personnel were aware that barium salts could cause these symptoms and none of them could believe that soluble barium salts could have been given to the patients. The second and third patients came to E.D. almost immediately and only then did physicians recognize an epidemic situation in which the common denominator was ingestion of barium salts. The lack of a Toxicologic Center, and time lost looking for information about toxic symptomatology, consequently delayed treatment. One of the patients died that night two hours and forty minutes after arrival. The rest of the patients received proper treatment (Potassium supplement and forced diuresis) and recovered after 72 hours. In the next two days 10 patients arrived with mild digestive symptoms. All of them were treated and discharged within the next 72 hours.

We think this report has great interest because it is the first massive intoxication with soluble salts used as routine contrast media, in the literature. It also is of interest to the police because the individuals that sold the barium sulfate to the hospital made a mistake with barium sulfite, with fatal consequences.

\section{NONINVASIVE ALTERNATIVES TO ARTERIAL BLOOD GASES IN OBESE PATIENTS}

\section{Carol L. Furgerson, M.D., Cleveland, Ohio, U.S.A.}

Morbidly obese patients are at increased risk of hypoventilation, hypoxia, and hypercarbia due to their increased $\mathrm{O}_{2}$ consumption, and $\mathrm{CO}_{2}$ production, in addition to restrictive lung disease secondary to their body habitus. While on a ventilator, or while being weaned from one, frequent arterial blood gases (ABGs) are required to monitor adequacy of ventilation. Repeated ABGs are painful and traumatic; noninvasive blood pressure measurement may render arterial line placement unnecessary and obesity make line placement/invasive monitoring difficult. Whether noninvasive monitors are useful alternatives to $\mathrm{ABG}$ for $\mathrm{PaCO}_{2}$ and $\mathrm{O}_{2}$ saturation (\%sat) measurements was studied on 10 morbidly obese patients having non-thoracic surgery under general anesthesia. End-tidal $\mathrm{CO}_{2}\left(\mathrm{EtCO}_{2}\right)$, pulse oximetry (\%sat) and $A B G$ values are simultaneously measured after 15 minutes, and as needed, during anesthesia. $\mathrm{EtCO}_{2}$ and $\mathrm{PaCO}_{2}$ values did not differ significantly $(p=.16)$. Mean $\mathrm{PaO}_{2}$ and oximetry \% sat. were statistically but not clinically significant ( 98.1 vs. $97.4 ; \mathrm{p}=.005)$.

Conclusion: end-tidal $\mathrm{CO}_{2}$ and pulse oximetry are reliable, noninvasive alternatives to invasive monitoring and $\mathrm{ABG}$ s in the ventilated morbidly obese patient.

\section{OXYGEN CONSUMPTION AND $\mathrm{CO}_{2}$ PRODUCTION IN CANINE HEMORRHAGIC SHOCK}

\author{
Ernest Benjamin, M.D., Thomas J. Iberti, M.D., \\ Kathleen M. Kelly, M.D., David P. Katz, M.D. \\ and Mark J. Rosen, M.D., New York, \\ New York, U.S.A.
}

In a canine hemorrhagic shock model, we studied the time course of systemic oxygen consumption $\left(\mathrm{VO}_{2}\right)$ and $\mathrm{CO}_{2}$ production $\left(\mathrm{VCO}_{2}\right)$ to determine the relative contribution of aerobic and anaerobic metabolism. Six dogs were anesthetized, paralyzed, ventilated and hemodynamically monitored. Respiratory gases were analyzed using a Metabolic Gas Monitor II (Utah Med). Hypotension was induced and maintained at $40-45 \mathrm{mmHg}$ by controlled hemorrhage, and values followed for $6 \mathrm{hr}$. Shock was associated with significant metabolic acidosis secondary to hyperlactatemia. $\left({ }^{*} \mathrm{p}<0.05\right)$.

\begin{tabular}{llccc} 
VARIABLES & BASELINE & HOE $+1 \mathrm{H}$ & HOE $+3 H$ & HOE + 5H \\
\hline BLOOD LOSS & $67 \pm 103$ & $892 \pm 162$ & $833 \pm 374$ & $983 \pm 150$ \\
$\mathrm{CI}$ & $4.3 \pm 0.9$ & $0.9 \pm 0.3 *$ & $1.2 \pm 0.2 *$ & $1.2 \pm 0.3$ \\
$\mathrm{PVO}_{2}$ & $68 \pm 11$ & $27 \pm 5 *$ & $29 \pm 4 *$ & $28 \pm 5$ \\
$\mathrm{PVCO}_{2}$ & $42 \pm 4$ & $69 \pm 10 *$ & $72 \pm 10 *$ & $64 \pm 11 *$ \\
$\mathrm{VO}_{2}$ & $94 \pm 25$ & $75 \pm 25$ & $83 \pm 25$ & $84 \pm 24$ \\
$\mathrm{VCO}_{2}$ & $82 \pm 18$ & $64 \pm 18$ & $85 \pm 25$ & $88 \pm 25$ \\
$\mathrm{RQ}$ & $.87 \pm .06$ & $.85 \pm .07$ & $1.03 \pm .15 *$ & $1.04 \pm .08 *$ \\
\hline
\end{tabular}

The results demonstrate that a significant increase in $\mathrm{CI}$ had little effect upon $\mathrm{VO}_{2}$, and that preservation of aerobic metabolism was the result of increased $\mathrm{O}_{2}$ extraction. The increased $\mathrm{VCO}_{2}$ may be one of the causes of venous hypercarbia. It is unclear whether the increased $R Q$ is due to aerobic combustion of predominantly CHO fuels, from anaerobic decarboxylation, or from lactic acid buffering. 